\title{
Endemic fluorosis with neurological complications in a Hampshire man
}

\author{
M. M. WEBB-PEPLOE AND W. G. BRADLEY \\ From The Royal South Hants Hospital, Southampton, and the Department of Neurological Surgery, \\ The Radcliffe Infirmary, Oxford.
}

Only a few comparatively minor bone changes attributed to naturally occurring fluorine in water supplies have been reported in Britain, and in a recent review Doig (1963) concluded that endemic fluorosis is practically unknown in Britain, except for mottling of the teeth. Severe endemic skeletal fluorosis has, however, been reported from many other parts of the world.

We describe below a case of skeletal fluorosis occurring in a Hampshire man who presented with neurological complications, and whose condition was appreciably improved by operation. We believe that this is the first case of its kind to be reported from Britain, and also the first case of skeletal fluorosis with neurological involvement in which surgery has been attempted with benefit.

\section{CASE HISTORY}

G.K., a 57-year-old carpenter from Nursling near Southampton, was admitted to the Royal South Hants Hospital on 1 April 1964 complaining of progressive weakness of the legs. In 1956 he fell 12 feet from a ladder, landing on his feet and buttocks, and noticed an immediate burning pain in both groins and back, with numbness and paralysis of both legs lasting about half an hour. He made a good recovery, and resumed work two weeks after the fall, but continued to notice pain and weakness of the left ankle, and occasional pain in the lumbar region.

In February 1959 he was seen as an out-patient complaining of progressive stiffness of both legs for three months, with discomfort in the calves after walking for an hour. He had occasional flexor spasms, but noticed no sphincter disturbance. Examination showed limitation of movement of the right hip, reduction in power of all leg muscles, pathologically brisk knee and ankle jerks, bilateral extensor plantar responses with preservation of the abdominal and cremasteric reflexes, and absent vibration sense below both iliac crests with no other sensory loss. He was advised to come into hospital for further investigations, but did not do so.

In November 1959 he saw an orthopoedic surgeon because of pain in the lower lumbar region radiating to the groins and the inner aspects of both thighs on bend-

Address for reprints: Dr. W. G. Bradley, Newcastle General Hospital, Westgate Road, Newcastle upon Tyne, 4. ing. Examination showed tenderness in the lumbosacral region, with limited and painful movements of the lumbar spine. Radiographs revealed marked sclerosis of the pelvis and lumbar vertebral bodies thought at that time to be due to Paget's disease. The pain was attributed to osteoarthritis, and he was given a surgical corset.

In March 1963 he again complained of pain in the lumbar region, and his radiographs were shown to Dr. Ronald Murray who diagnosed skeletal fluorosis. In July 1963 he fell, injuring his right shoulder, and in November of that year, following another fall, he again experienced girdle-like pain in the groins with numbness and paralysis of the legs. The pain lasted for two days, and from that time he noticed numbness and pain in the legs on standing, a right footdrop, and urgency of micturition with occasional urinary incontinence on standing up.

In the two months before admission his legs became progressively weaker, with troublesome flexor spasms, and fluttering sensations in the hamstrings.

The family history was unhelpful. The patient's wife had died at the age of $\mathbf{3 2}$ of disease of the spine, but further details were not available. His son and daughter were both in good health, their teeth were not mottled, and radiographs of the former's spine and pelvis were normal.

The patient himself had had all his teeth extracted on account of caries when he was $\mathbf{4 0}$ years old.

On examination he was an obese, muscular, middleaged man $5 \mathrm{ft} .5 \mathrm{in}$. in height, with a marked lumbar lordosis, who was only able to stand and walk with the aid of two sticks. There was moderate restriction of all movements of both hips, crepitus without deformity of both knees, and limitation of the movements of both elbows to the range of $50^{\circ}$ to $140^{\circ}$. The movements of the whole spine were restricted, with tenderness over the T12 and L1 vertebrae. The glutei and right hamstring muscles were wasted, and there was coarse fasciculation of the thigh and calf muscles of both legs. He had a bilateral spastic footdrop more marked on the right than the left, with generalized weakness of all leg muscles. Tone was increased in the legs with exaggerated deep tendon reflexes, and both plantar responses were extensor. The abdominal reflexes were preserved. An indefinite sensory level to pain, light touch, and temperature sensation was noted at L1, the sensory loss being more marked over the L2 to S1 dermatomes on the right, and the L2 to L4 dermatomes on the left. Vibration sense was 
absent below both iliac crests, but position sense in the toes was normal. General medical examination was normal; blood pressure was $180 / 70 \mathrm{~mm} . \mathrm{Hg}$, and all peripheral pulses were present.

INVESTIGATIONS Haemoglobin was $15 \cdot 2$ g. \%, W.B.C. 4,500/c.mm., with a normal differential count; E.S.R. $15 \mathrm{~mm}$. in one hour (Westergren); serum albumin $3.4 \mathrm{~g}$. and globslin $2.6 \mathrm{~g}$. per $100 \mathrm{ml}$. Serum electrolytes were normal. Blood urea was $42 \mathrm{mg}$. per $100 \mathrm{ml}$. Total serum cholesterol was $260 \mathrm{mg}$., total fasting serum calcium $9.6 \mathrm{mg}$., and inorganic phosphate $24 \mathrm{mg}$. per $100 \mathrm{ml}$.; serum alkaline phosphatase 10 , and acid phosphatase 1.6 K.A. units. Blood Wassermann and P.P. reactions were negative.

The cerebrospinal fluid was clear and colourless under normal pressure, containing $25 \mathrm{mg}$. protein per $100 \mathrm{ml}$. (no excess globulin), and 1 lymphocyte perc.mm., and the Wassermann and P.P. reactions were negative. On a chest radiograph details were obscured by dense rib shadows. Heart size was normal and lung fields were clear. Radiographs of the pelvis and lumbar spine (Figs. 1 and 2) showed a generalized increase in bone density, with prominent bone spurs at the site of tendon insertions around both iliac and pubic regions, and marked virtebral lipping. Radiographs of both elbows (Fig 3) showed changes similar to those seen in the pelvis and spine, with superadded osteoarthritis. On the first screening (Fig. 4) a myelogram showed an almost complete obstruction to the flow of Myodil at the level of the body of the eleventh thoracic vertebra. Five days later the same Myodil passed freely up the spinal canal, but there was an extradural constriction of the theca at T11, more marked posteriorly and to the right.

The patient was referred to Mr. J. Pennybacker at the Radcliffe Infirmary, Oxford, who agreed that the myelopathy was probably related to the local vertebral disease. He carried out a lower dorsal laminectomy and decompression of the lower thoracic cord on 16 April 1964.

OPERATIVE FINDINGS The laminae and spines of T10, T11, and T12 were removed. The bone had a normal naked-eye appearance, but was exceptionally thick and hard, especially that of the eleventh thoracic vertebra. The laminae at this level were very thick (up to $2 \mathrm{~cm}$.), and when they had been removed the theca was seen to be pinched. Below this level (opposite T12), and above it (opposite T10), the vertebral canal was only slightly narrowed, and there was a generous layer of extrathecal fat which was absent over T11.

POST-OPERATIVE COURSE This was uneventful apart from transient urinary retention. The motor and sensory loss in the legs slowly regressed, the urgency and occasional incontinence of urine disappeared, and three months after operation the patient was able to walk 50 yards with the aid of one stick and a right toespring. When last seen in May 1965 he was managing light work with a packing firm, could move freely about the house with one stick, and walk long distances with two sticks. Power in the lower limbs was good, especially in the pelvic girdle muscles. Tone was still increased, particularly in the

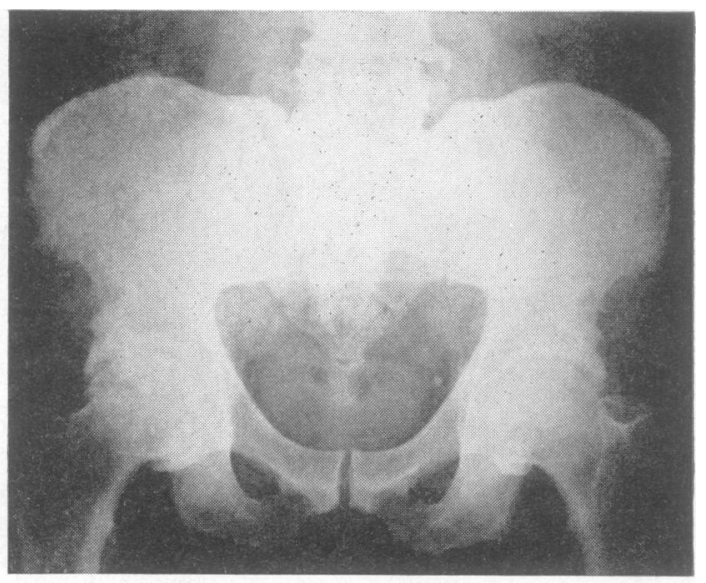

FIG. 1.

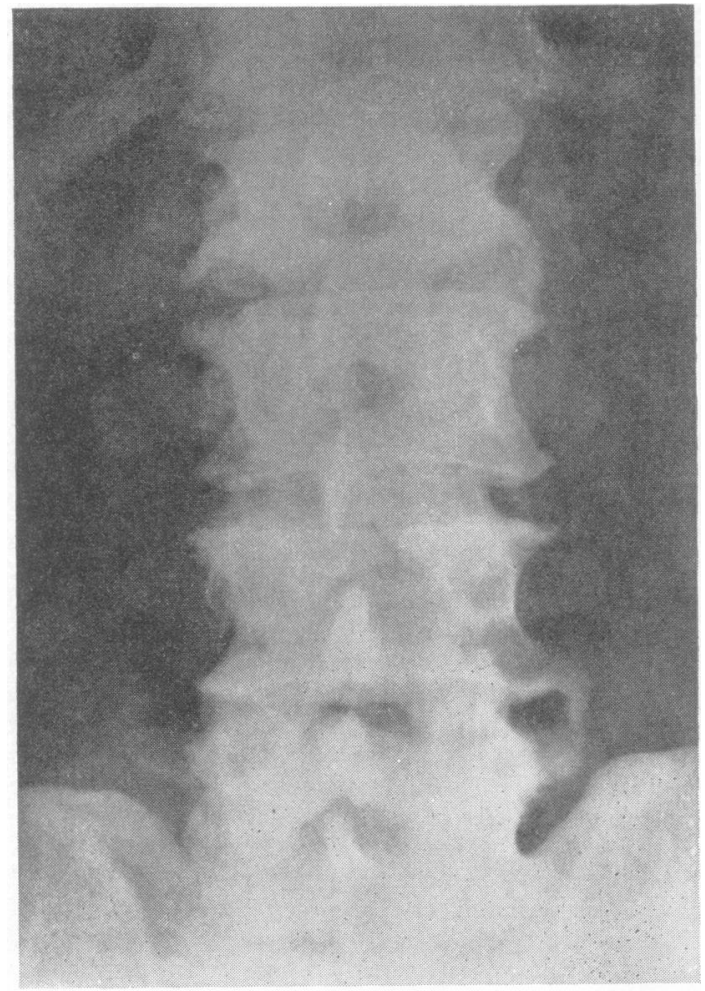

FIG. 2.

FIGS. 1 and 2. Radiographs of pelvis and lumbar spine showing generalized increase in bone density, prominent bone spurs at the site of tendon insertions, and marked vertebral lipping. 


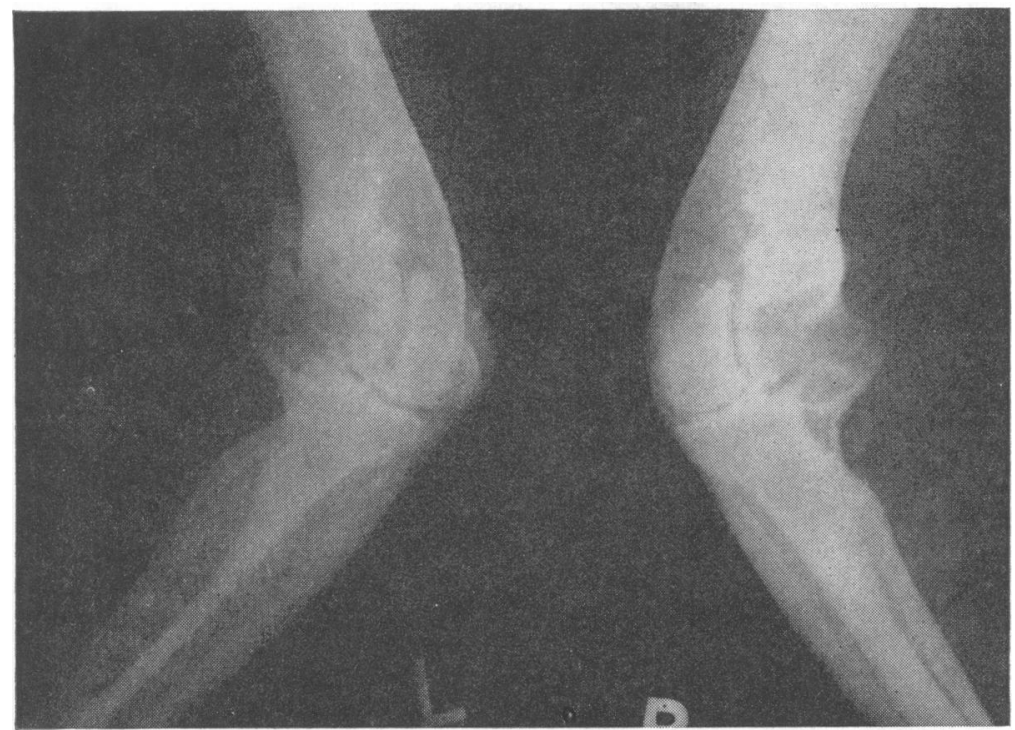

FIG. 3. Radiograph of both elbows showing changes similar to those seen in the pelvis and spine, with superadded osteoarthritis.

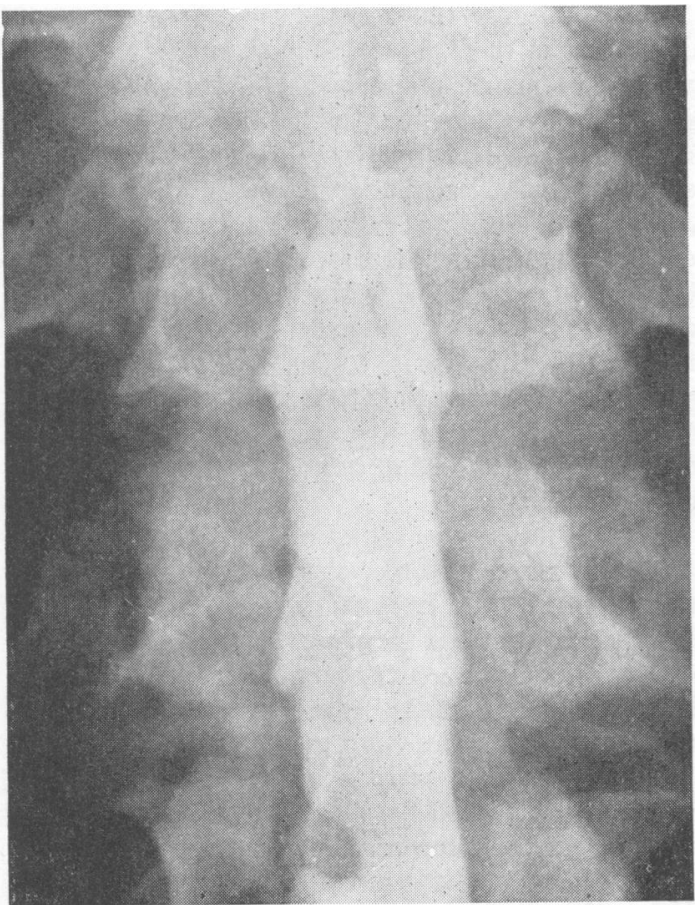

FIG. 4.

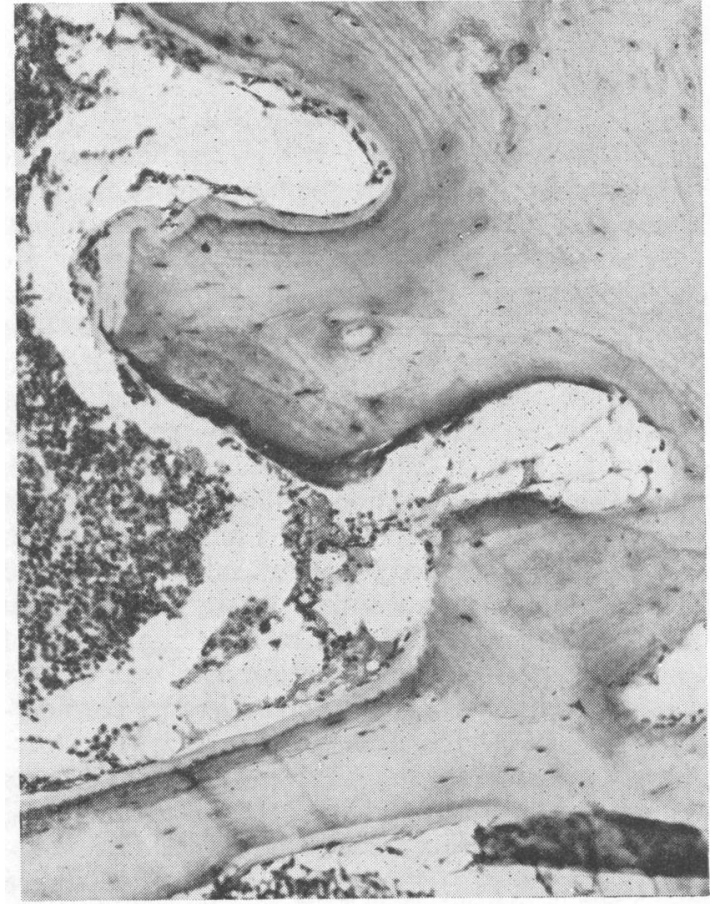

FIG. 5 .

FIG. 4. Myelogram showing almost complete obstruction to the flow of Myodil at the level of the body of T11, despite a steep Trendelenberg tilt.

FIG. 5. Photomicrograph $(\times 70)$ showing 'osteoid seams' in bone removed at operation. 
calves, and all deep tendon reflexes in the legs were exaggerated, with bilateral extensor plantar responses. Pain and position senses were normal, and he had full control of his bladder.

Histology OF BONE REMOVED AT OPERATION Dr. D. Oppenheimer reported that the compact and spongy bone contained normal haemopoietic marrow, and showed no gross abnormality. So-called 'osteoid seams' were prominent in places (Fig. 5), and there were signs of osteoblastic activity. Attached to one specimen was some disc fibro-cartilage showing calcification.

FLUORIDE ANALYSIS The fluoride content of the patient's blood, urine, and bone, together with that of two water samples, were estimated using thorium nitrate titration (Table). The two water samples contained negligible amounts of fluoride. The patient's blood and urine contained normal amounts of fluoride, but the fluoride content of bone was approximately twice the upper limit of normal.

ANALYSIS OF FLUORIDE

\begin{tabular}{lll} 
& Patient & Normal Range \\
\hline Blood (mg./100 ml.) & $<0.02$ & Traces (Roholm, 1937) \\
Urine (mg./100 ml.) & $<0.02$ & $<0.37$ (Sinclair, 1949) \\
Bone (mg./100 g. bone ash) & 253 & $<130$ (Roholm, 1937; \\
& & Zipkin et al., 1958) \\
Water sample 1 & No detectable fluoride \\
Water sample 2 & No detectable fluoride
\end{tabular}

\section{DISCUSSION}

The diagnosis of fluorosis in this case rests on the radiographic appearances, the histology of the bone removed at operation, and the bone fluoride content.

The radiographic appearances of fluorosis are characteristic and diagnostic (Møller and Gudjonsson, 1932), and were described by Roholm (1937) as follows: ' . . . the affection is a system disease, for it attacks all bones, though it has a predilection for certain places. The pathological process may be characterized as a diffuse osteosclerosis, in which the pathological formation of bone starts both in periosteum and in endosteum. Compacta densifies and thickens; the spongiosa trabeculae thicken and fuse together. The medullary cavity decreases in diameter. There is considerable new formation of bone from periosteum, and ligaments that do not calcify or only in advanced age undergo a considerable degree of calcification. All signs of bone destruction are absent from the picture .... The changes are usually most marked in the pelvis, spine, ribs, and lower limbs, with calcification of the intervertebral ligaments producing a 'poker spine' in severe cases. 'Rose thorn' multiple exostoses may give the appearance of hoar frost, as in the remarkable thorax shown by Lyth (1946). The radiographs of our case (see Figs. 1, 2, and 3) show the typical changes of severe skeletal fluorosis. Bones subjected to greatest stress are most affected, probably due to their greater calcium turnover, and in India where loads are carried on the head, the most marked changes are often found in the cervical spine. The severe elbow involvement in our case (see Fig. 3) may have been related to his occupation as a carpenter.

Histological data on endemic fluorosis are scanty, and largely limited to studies in experimental animals. Singh and Jolly (1961) were, however, able to study the histopathology in seven of the 60 patients in their series. The long bones showed two zones of bony tissue: the compacta, and a thin irregular peripheral tissue resembling spongy bone. Examination of the compacta revealed disordered lamellar orientation, and an enlarged poorly formed Haversian system. In the spongy bone (iliac crest and vertebral bodies), islands of osteoid tissue ('osteoid seams') were found among well-formed bone trabeculae which were very dense in places and contained a considerable amount of calcium. The bone removed at operation in our case showed prominent 'osteoid seams', supporting the diagnosis of fluorosis (see Fig. 5).

The fluoride content of our patient's bone was $253 \mathrm{mg}$. fluoride/100 g. bone ash. Roholm (1937) found a level of $93 \pm 43.6 \mathrm{mg}$. fluoride $/ 100 \mathrm{~g}$. bone ash in the ribs of 11 normal subjects, whereas the bones of two workers with industrial fluorosis contained 850 and $1,010 \mathrm{mg}$. fluoride/100 g. bone ash respectively. In another series (Zipkin, McClure, Leone, and Lee, 1958), the fluoride content of vertebral bone ranged from $802 \pm 109 \mathrm{mg}$. fluoride/ $100 \mathrm{~g}$. ash in regions where the drinking water contained 4 p.p.m. fluoride, to $112 \pm 10 \mathrm{mg}$. fluoride $/ 100 \mathrm{~g}$. in areas where the drinking water contained less than 1 p.p.m. fluoride. Singh and Jolly (1961) found an average of 343 (range 70 to 680) $\mathrm{mg}$. fluoride/100 g. bone ash in their cases of endemic fluorosis.

Fluoride turn-over studies in man (Largent, 1960) show that normal subjects soon attain a balance between intake and output, probably after a rough equilibrium is gained in which the skeleton reaches and maintains a given concentration level. With an abnormally high intake, more fluoride is retained until the body reaches 'saturation', when the rate of accumulation decreases. Once the fluoride intake is reduced, the retained fluoride is released slowly and at a progressively diminishing rate. Brun, Buckwald, and Roholm (1941) observed that cryolite workers continued to excrete large quantities of fluoride in the urine for some years after exposure had ceased. This fluoride probably came from the breaking down of pathological bone tissue, for the ex-miners showed less osteosclerosis than those actually at 
work. The fact that our patient's blood and urinary fluoride levels were both within normal limits despite the increased bone content suggests that the intoxication had occurred several years previously, and that he was no longer ingesting large amounts of fluoride when he came under our care.

The original cases of skeletal fluorosis occurred in those engaged in the recovery of aluminium from cryolite, a double fluoride of sodium and aluminium (Feil, 1930; Møller and Gudjonsson, 1932; Roholm, 1937), but it is now known that there are some 28 industrial occupations associated with fluoride hazard (Allcroft, 1959). In areas, where the drinking water has a relatively high fluoride content, large amounts of the element may be accumulated in the body leading to chronic fluorosis. This type of intoxication ('endemic fluorosis') was first reported from India (Shortt, McRobert, Barnard, and Nayar, 1937a; Shortt, Pandit, and Raghavachari, 1937b). Since then sporadic cases have also been recognized in Ceylon (Clark, 1942), China (Lyth, 1946), Japan (Dean and McKay, 1939), Argentina (Mascheroni, Munoz, and Reussi, 1939), North Africa (Pinet, Pinet, Barrière, and Bouche, 1961), South Africa (Ockerse, 1941; Dodd, Levy, Jackson, and Traut, 1960), the United States (Linsman and McMurray, 1943; Stevenson and Watson, 1960), Saudi Arabia El Tannir (1959), and Aden (Kumar and Kemp Harper, 1963). It should be noted that these reports all come from areas with a hot climate where people drink a great deal of water.

In Britain, Kemp, Murray, and Wilson (1942) reported an apparently high incidence of osteochondritis of the spine associated with dental fluorosis in children from the villages of Bampton and Launton in Oxfordshire, and from Malden in Essex. The well water used in the Oxfordshire villages contained only 0.3 to 1.2 p.p.m. fluoride, but Malden's water supply has the highest fluoride content in Britain ( 5 p.p.m.). A later more extensive study failed to confirm these observations (Eley, Kemp, Kerley, and Berry, 1957).

Involvement of the nervous system in skeletal fluorosis has been reported almost exclusively from India. Shortt et al. (1937a and b) found evidence of spinal cord involvement in $\mathbf{1 0}$ of their cases from the Nellore district of Madras, with impotence, sphincter disturbances, ankle and patellar clonus, and depressed pain and temperature sensation. Rao (1955) described paraplegia due to spinal cord compression in a 45-year-old man with fluorosis. Siddiqui (1955) reported 32 cases with ages ranging from 22 to 50 years, who had signs of spinal cord and eighth nerve damage, and whose drinking water contained between 5 and 12 p.p.m. fluoride. In 27 of their 60 cases from the Punjab, Singh and Jolly (1961) found neurological involvement, which they ascribed to both radiculopathy and myelopathy. The former gave rise to muscle wasting, acroparaesthesiae, and referred pain, whereas the latter usually presented as weakness and spasticity of the limbs, often with a sensory level. The radiculopathy was due to narrowing of the intervertebral foramina by thickened bone leading to root compression. The myelopathy was due to narrowing of the spinal canal, and in one case studied at necropsy the antero-posterior diameter of the canal was reduced to a mere $3 \mathrm{~mm}$. at the level of the third and fourth cervical vertebrae. In some cases exostoses arising from the posterior surfaces of the vertebral bodies caused backward displacement and compression of the spinal cord against the ligamentum flavum and laminae. In other patients it was the laminae themselves that were thickened. In the more severe cases the narrowing of the spinal canal led to obstruction as shown by cerebrospinal fluid manometry and myelography. Many of these authors remarked on the serious exacerbation of symptoms and signs that often followed quite minor falls, and Lyth (1946) described a Chinaman with severe endemic fluorosis who died of a fractured neck after a minor fall. Symonds (1953) has emphasized the importance of minor injuries damaging the cord where the spinal canal is narrowed by cervical spondylosis, and the same would appear to be true for this condition. Our patient's symptoms became very much worse following a series of falls, and in his case the spinal cord compression, largely localized to T11 (see Fig. 4), was due to thickening of the laminae. Following decompression, there was an obvious improvement in symptoms and signs.

Similar thickening of the laminae of the lumbar vertebrae causing neurologial damage has been reported by Teng and Papatheodoru (1963) and by Joffe, Appleby, and Arjona (1966), though in those cases there was no generalized bony sclerosis to suggest the diagnosis of systemic fluorosis.

The source of our patient's fluoride intoxication remained obscure. He had worked all his life as a carpenter, and there was no history of exposure to fluorides in his work. Suspicion therefore rested on his drinking water and diet. In Britain the fluoride content of water ranges from a trace to 5 p.p.m. Tea contains an average of 56 p.p.m. fluoride (fresh weight), but may contain as much as 399 p.p.m. (Cholak. 1960). The edible species of fish contain an average of 9.4 p.p.m. fluoride. The average British daily fluoride intake is low, and has been estimated at $1.8 \mathrm{mg}$. for men, $1.3 \mathrm{mg}$. for women, and $0.6 \mathrm{mg}$. for children (Lancet, 1960). Our patient was a heavy tea drinker, but otherwise did not consume large amounts of food rich in fluoride. 
Brun et al. (1941) believed that a daily intake of $28 \mathrm{mg}$. of fluoride over many years was necessary for the development of skeletal fluorosis, but later workers place the figure at about $20 \mathrm{mg}$. per day (Hodge, 1960). Racial, climatic, and nutritional factors may also be important in determining the incidence of the disease in a population exposed to high water fluoride levels. Zipkin et al. (1958) found that north American subjects drinking water containing 8 p.p.m. fluoride had bone fluoride levels quite as high as those found in the Indian cases of severe skeletal fluorosis described by Singh and Jolly (1961) and yet they showed no radiological signs of the disease. Calcium has been thought to decrease the toxicity of fluoride, and some workers believe that soft water from surface wells can produce bone changes at quite low fluoride concentrations (Sinclair, 1964). Burrowes (1960) gained the impression that in a fairly high fluoride area ( 3.5 p.p.m.) the most severe dental mottling was seen in children who were tea drinkers, while it was much less in those whose main drink was milk.

Our patient spent his first 28 years of life at Milford-on-Sea in Hampshire, during which time he drank the mains water from the river Avon at Christchurch (fluoride content $0 \cdot 1$ p.p.m.). From 1935 to 1940 (aged 28 to 33 years) he lived at Stratton in Cornwall, where his drinking water came from the river Tamar (fluoride content 0.04 p.p.m.). In 1940 he moved to Nursling near Southampton, and from 1940 to 1945 (aged 33 to 38 years) drank water from a well in his garden. In 1945 his cottage was supplied with mains water at low fluoride content, and the well was bricked up. Permission to unblock this well was refused, so we have been unable to analyse this water. Water from a spring about a mile from the cottage contained no detectable fluoride (water sample 1 in Table). From 1946 to 1961 he worked at the Lockerley War Department camp near Romsey, and in his work-time tea drank water from two bores that are no longer in use. We were able to obtain an unsatisfactory surface sample from one of the bores which also contained no detectable fluoride (water sample 2 in Table). The highest fluoride content in any present public supply of water within the county of Hampshire is 1 to 1.25 p.p.m. in a tiny area on its northern fringe supplied by the Thames Valley Water Board.

The following facts would appear to be relevant to any attempt at determining the source and time of our patient's intoxication. Up to the age of 33 his drinking water was known to have a low fluoride content. He first developed symptoms of fluorosis at the age of 49, and was known to have radiographic evidence of osteosclerosis at the age of 51. (Crippling osteosclerosis usually appears some 10 to 20 years after the ingestion of the fluoride.) At the age of 57, fluoride estimations showed normal blood and urinary levels, but a bone content about twice the upper limit of normal, suggesting that the intoxication had occurred many years previously, and that it had ceased at least three years before the estimations were made. In the light of these facts, suspicion appears to rest on the cottage well that supplied our patient with drinking water from 1940 to 1945 , and it is unfortunate that all our efforts to confirm this by analysing the necessary water sample have proved unsuccessful.

\section{SUMMARY}

The case of a 57-year-old man with skeletal fluorosis leading to spinal cord compression is described. Myelography showed a partial block at T11, and following decompression of the lower thoracic cord there was considerable improvement in symptoms and signs. The diagnosis of fluorosis was confirmed by the radiological appearances, by the histology of the bone removed at operation, and by the raised level of the bone fluoride.

The possible sources of intoxication are discussed, and a brief survey made of the literature, with special reference to the neurological complications of $\frac{}{\mathbb{Q}}$ skeletal fluorosis. This is believed to be the first case of severe skeletal fluorosis with neurological involvement to be reported from Britain, and also the first such case to undergo surgery with benefit.

We should like to thank Dr. K. M. Robertson and Mr.尹 J. Pennybacker for permission to report this case, and Mr. D. E. Macrae and Mr. A. J. M. Birnie who first referred the case to us at Southampton. We are most grateful to Dr. Oppenheimer for the histology, and to Mr. David Brown and Mr. G. A. Higgins, of the Department of Clinical Biochemistry, Radcliffe Infirmary, for the fluoride estimations. Finally we would like to express our appreciation of the help given us by Dr. I. A. MacDougall, Hampshire County Medical Officer of Health, and Dr. W. Paterson, Medical Officer of Health for Launceston in Cornwall, in our efforts to trace the fluoride contents of the waters drunk by our patient.

\section{REFERENCES}

Allcroft, R. (1959). Fluorosis in farm animals. In The Effects of Pollution on Living Material, ed. W. P. Yapp pp .95-102. (Symposia of the Institute of Biology, No. 8.) London.

Brun, G. C., Buckwald, H., and Roholm, K. (1941). Die Fluorausscheidung im Harn bei chronischer Fluorvegiftung von Kryolitharbeitern. Acta med. scand., 106, 261-273.

Burrowes, H. P. (1960). Fluoridation. Lancet, 1, 701.

Cholak, J. (1960). Current information on the quantities of fluoride found in air, food, and water. A.M.A. Arch. industr. Hlth, 21 , 312-315.

Clark, A. (1942). Further notes on the effects of inhibitory substances in foods. J. trop. Med. Hyg., 45, 49-52. 
Dean, H. T., and McKay, F. S. (1939). Production of mottled enamel halted by a change in common water supply. Amer. J. publ. Hlth, 29, 590-596.

Dodd, N. F., Levy, D. W., Jackson, W. P., and Traut, M. L. (1960). Environmental bone disease of hitherto undescribed type. S. Afr. med. J., 34, 606-611.

Doig, A. T. (1963). Fluorosis. Practitioner, 190, 622-627.

El Tannir. M. D. (1959). Mottling of enamel in Mecca and the Arabian Peninsula. Amer. J. publ. Hlth, 49, 45-52.

Eley, A. J., Kemp, F. H., Kerley, P. J., and Berry, W. T. (1957). The incidence of spinal defects in high and low fluoride areas. Lancet, 2, 712-713.

Feil, A. (1930). Le fluorisme professionnel. Paris méd., 2, 242-248.

Hodge, Fi. C. (1960). Notes on the effect of fluoride deposition on body tissues. A.M.A. Arch. industr. Hlth, 21, 350-352.

Joffe, R., Appleby, A., and Arjona, V. (1966). Intermittent ischaemia of the cauda equina due to stenosis of the lumbar canal. J. Ne'ırol. Neurosurg. Psychiat., 29, 315-318

Kemp, F. H., Murray, M. M., and Wilson, D. C. (1942). Spondylosis deformans in relation to fluorine and general nutrition. Lancet, 2, 93-96.

Kumar, S. P., and Kemp Harper, R. A. (1963). Fluorosis in Aden. Brit. J. Radiol., 36, 497-502.

Lancet (1960). Occasional Survey: Medical and biological aspects of fluoridation. 2, 425-428.

Largent, E. J. (1960). The metabolism of fluorides in man. A.M.A. Arch. industr. Hlth, 21, 318-323.

Linsman, J. F., and McMurray, C. A. (1943). Fluoride osteosclerosis from drinking water. Radiology, 40, 474-483.

Lyth, O. (1946). Endemic fluorosis in Kweichow, China. Lancet, 1, 233-235.

Mascheroni, H. A., Munoz, J. M., and Reussi, C. (1939). Quoted by Waldbott, G. L. (1956). Incipient fluorine intoxication from drinking water. Acta med. scand., 156, 157-168.

Møller, P. F., and Gudjonsson, S. V. (1932). Massive fluorosis in bones and ligaments. Acta radiol. scand., 13, 269-294.

Ockerse, T. (1941). Endemic fluorosis in the Pretoria District. $S$. Afr med. J., 15, 261-266.

Pinet, F., Pinet, A., Barrière, J., and Bouche, B. (1961). Les fluoroses endémiques d'origine hydrique du souf. Algérie méd., 65, 737-749.

Rao, S. V. (1955). Skeletal fluorosis. J. Indian med. Prof., 2, 780-783. Roholm, K. (1937). Fluorine Intoxication. Lewis, London.

Shortt, H. E., McRobert, G. R., Barnard, T. W., and Nayar, A.S.M. (1937a). Endemic fluorosis in the Madras Presidency. Indian J. med. Res., 25, 553-568.

— Pandit, C. G., and Raghavachari, T. N. S. (1937b). Endemic fluorosis in the Nellore district of South India. Indian med. Gaz., 72, 396-398.

Siddiqui, A. H. (1955). Fluorosis in Nalgonda district, HyderabadDeccan. Brit. med. J., 2, 1408-1413.

Sinclair, H. M. (1964). Fluoridation falsified. Ibid., 1, 554

Sinclair, K. J. (1949). The toxicity of fluorine compounds. A review of the literature. In Industrial Fluorosis, Med. Res. Cour. Memo. No. 22, pp. 97-119.

Singh, A., and Jolly, S. S. (1961). Endemic fluorosis. Quart. J. Med., 30, 357-372.

Stevenson, C. A., and Watson, A. R. (1960). Roentgenological findings in fluoride osteosclerosis. A.M.A. Arch. industr. Hlth, 21, 340

Symonds, C. (1953). The interrelation of trauma and cervical spondylosis in compression of the cervical cord. Lancet, 1, 451-454.

Teng, P., and Papatheodorou, C. (1963). Lumbar spondylosis with compression of the cauda equina. Arch. Neurol. 8, 221-229.

Zipkin, I., McClure, F. J., Leone, N. C., and Lee, W. A. (1958). Fluoride deposition in human bones after prolonged ingestion of fluoride in drinking water. Publ. Hlth. Rep. (Wash)., 73, 732-740.

\section{The October 1966 Issue}

\section{THE OCTOBER 1966 ISSUE CONTAINS THE FOLLOWING PAPERS}

Source of the midline echo and its implications in echoencephalography T. R. FISHER

Beta wave activity in the electroencephalogram in cases of coma due to acute brain-stem lesions ЕIICHI отомо The electroencephalogram in veganism, vegetarianism, vitamin $B_{12}$ deficiency, and in controls ERIC D. WEST and FREY R. ELLIS

Autoregulation of cerebral blood flow: influence of the arterial blood pressure on the blood flow through the cerebral cortex A. MURRAY HARPER

Experimental intracranial pressure gradients in the human skull L. M. THOMAS, V. L. ROBERTS, and E. S. GURDJIAN

Phytanic acid in Refsum's syndrome w. STEWART ALEXANDER

Refsum's disease: A disorder of lipid metabolism MARK RAKE and MICHAEL SAUNDERS

Evalution of the role of neurosurgical procedures in the pathogenesis of secondary brain-stem haemorrhages GORDON K. KLINTWORTH

Strio-pallidal projection in the monkey w. M. CowAN and T. P. S. POWELL
Excitability of muscle fibre membranes in dystrophic mice A. J. McComas and s. J. MOSSAWY

Cerebral oedema and the water content of normal white matter MASAZUMI ADACHI and IRWIN FEIGIN

Hypertensive disease and cerebral oedema MASAZUMI ADACHI, WILLIAM I. ROSENBLUM, and IRWIN FEIGIN

Immunological study of chronic polyneuropathies of undetermined cause B. O. OSUNTOKUN, JOHN PRINEAS, and E. J. FIELD

Two cases of accidental hypothermia in Parkinson's disease with unusual E.E.G. findings s. S. GUBBAY and D. D. BARWICK

Speech and other functions after left (dominant) hemispherectomy AARON SMITH

E.E.G. studies in the syndrome of isolated episodes of confusion with amnesia, 'transient global amnesia' $\mathbf{R}$. JAFFE and M. B. BENDER

Proceeding of the Society of British Neurological Surgeons

Book reviews

Copies are still available and may be obtained from the PUBLISHING MANAGER, BRITISH MEDICAL ASSOCIATION, TAVISTOCK SQUARE, W. c. 1., price 18s. 6D. 